\title{
Perceived Stress and Psychiatric Symptoms in Swedish Upper Secondary School Students
}

\author{
Frida Thorsen ${ }^{1}$, Carl Antonson ${ }^{1}$, Jan Sundquist ${ }^{1} \&$ Kristina Sundquist ${ }^{1}$ \\ ${ }^{1}$ Center for Primary Health Care Research, Department of Clinical Sciences, Malmö, Lund University, Region \\ Skåne, Sweden \\ Correspondence: Frida Thorsen, Clinical Research Centre (CRC), Building 28, Floor 11, Jan Waldenströms gata \\ 35, Skåne University Hospital, SE-205 02 Malmö, Sweden. Tel: 46-709-34-9782. E-mail: \\ frida.thorsen@gmail.com
}

Received: April 11, 2016

doi:10.5539/jedp.v6n2p183

\begin{abstract}
Background: Previous studies in adolescents have rarely used validated questionnaires to assess stress and psychiatric symptoms. The first aim of this study, which was conducted in 2011, was to examine the prevalence and potential sex differences of perceived stress and psychiatric symptoms among Swedish upper secondary school students for comparison with Swedish reference populations from 1996 and 1998. The second aim was to examine the correlation between perceived stress and psychiatric symptoms in 2011. Methods: Perceived stress and psychiatric symptoms were measured in 194 Swedish students, aged 15-19 years, with the validated questionnaires Perceived Stress Scale (PSS-14) and Symptoms Checklist 90 (SCL-90). PSS-14 data were compared with data from the 1996 study. SCL-90 data were compared with a large Swedish reference sample from 1998. clinicaltrials.gov: NCT01457222. Results: Significantly higher PSS-14 scores (more stress) and Global Severity Index scores (from SCL-90) (more psychiatric symptoms) were found in both sexes compared with the reference groups. Although no sex difference was found in perceived stress, female students showed more psychiatric symptoms than male students. Perceived stress and psychiatric symptoms were well correlated $(\rho=0.67)$. Conclusions: Using validated scales, this study shows that Swedish adolescents reported higher levels of perceived stress and psychiatric symptoms in 2011, in comparison with Swedish reference populations from 1996 and 1998. Girls reported more psychiatric symptoms than the boys. Future studies could examine which strategies are useful to help young people improve in coping with stress and to prevent associated psychiatric symptoms.
\end{abstract}

Keywords: adolescence, gender, internalizing symptoms, stress

\section{Introduction}

Stress-related and psychiatric disorders are, according to the World Health Organization (WHO), the second most common non-communicable health concern worldwide (cardiovascular disease being the leading concern) (Murray et al., 2012; Murray, 1996). Psychiatric disorders affect almost all age groups. For example, depressive symptoms are the leading cause of disability worldwide in the age-group 10-24 years (Gore et al., 2011). As psychiatric problems may follow individuals into adulthood, child and adolescent psychiatric health is considered a key issue internationally (Gore et al., 2011; Patel, Flisher, Hetrick, \& McGorry, 2007; Ravens-Sieberer et al., 2009) as is shown by declarations adopted by the WHO and the EU (Beckman \& Hagquist, 2010), including Sweden.

In the near future, psychiatric disorders are expected to be the leading cause of public health problems in Sweden according to the Swedish National Institute of Public Health (Folkhälsoinstitutet, 2005). The Swedish 2008 Public Health Bill is congruent with the declarations adopted by the WHO and the EU; both organizations state that children and young people are a key target group and that psychiatric health is a key investment area in public health policy (Beckman \& Hagquist, 2010).

Previous research has shown that poor psychiatric health in adolescence is associated with a high prevalence of psychiatric problems in adulthood (Patel et al., 2007). Unaddressed psychosocial stress in adolescents increases the risk of developing physical and psychiatric problems as adults (Loeber \& Farrington, 2000) and a large 
proportion of all adult psychiatric disorders start in adolescence (Mathers \& Loncar, 2006). Symptoms such as anxiety, depression and insomnia during adolescence, as well as functional somatic symptoms, are associated with psychiatric disorders later in life (Bohman et al., 2012; Clark, Rodgers, Caldwell, Power, \& Stansfeld, 2007; Fergusson, Horwood, Ridder, \& Beautrais, 2005; Hiyoshi et al., 2015). Associations between perceived stress and subjective health complaints have also been observed (Hjern, Alfven, \& Ostberg, 2008; Torsheim \& Wold, 2001).

For public health concerns, it is important to assess the prevalence of stress-related and psychiatric symptoms among adolescents of today and whether a potential increase has occurred over time. Such studies have previously been conducted among Swedish children and adolescents (Bremberg, 2006; Landstedt \& Gådin, 2012; Nygren, Bergström, Janlert, \& Nygren, 2012; Petersen, 2007; Wiklund, Malmgren-Olsson, Öhman, Bergström, \& Fjellman Wiklund, 2012). Increases in anxiety, depressive symptoms, and somatization are observable among all age groups in society, except the oldest. People aged 16-24 years, and particularly young women, show much steeper increases in these symptoms than other age groups (Petersen, 2007). Psychiatric symptoms have also been proposed to be more common among Swedish youths today compared with two decades ago (Bremberg, 2006; Petersen, 2007; Wiklund et al., 2012). A report from the Public Health Agency of Sweden from 2009/2010 showed that this increase might have levelled off, but they are still reported twice as often as in the mid-1980s (Folkhälsomyndigheten, 2010). Data from 2012 shows that increases in worrying and anxiety have plateaued in girls and might even have decreased slightly in boys. Hospitalization for psychiatric disease has, however, increased in both sexes (Folkhälsomyndigheten, 2014).

A similar picture is reported by Statistics Sweden, the governmental census bureau, in the "Living conditions survey", based on face-to-face interviews performed annually since 1975. The survey shows an increase in psychiatric symptoms in both males and females aged 16-24 years over time and that boys report fewer symptoms than girls. Comparisons between years are difficult since different questions and age classifications have been used over time. Moreover, a new method for data collection (telephone interviews) was introduced in 2008, which makes it even more difficult to make comparisons with previous surveys (Bremberg, 2006).

One survey covering 2500-3000 students aged 15-16 that was conducted six times between 1988 and 2005 (Bremberg, 2006) reports that the frequency of "a feeling of sadness", "difficulty sleeping", "often or always suffered from headaches", and "felt tense" increased between 1988 and 2005 (Hagquist \& Forsberg, 2007). Another Swedish survey covering 500 students, 13-16 years of age, was conducted six times between 1990 and 2005. "Felt depressed", "suffering from headaches", and "suffering from pain" were reported more often in 1999 than in 1990 (Hagquist \& Forsberg, 2007).

However, it is important to note that most previous studies, albeit large-scale, have used only a limited number of questions assessing stress and psychiatric symptoms rather than validated questionnaires with high reliability. It has been stated that the lack of such studies makes interpretations of results and comparisons over time between studies and between sexes difficult (Bremberg, 2006; Petersen, 2007). In addition, there is still a shortage of epidemiological studies among older Swedish adolescents using validated questionnaires (Bremberg, 2006; Petersen, 2007), the use of the latter enabling comparisons of specific stress-related and psychiatric symptoms over time.

The first aim of this study, which was conducted in 2011, was to examine the prevalence and potential sex differences of perceived stress and psychiatric symptoms among Swedish upper secondary school students, for comparison with Swedish reference populations from 1996 and 1998. The second aim was to examine the correlation between perceived stress and psychiatric symptoms in 2011.

\section{Materials and Methods}

\subsection{Population}

This study is part of a larger project that aims to evaluate stress and psychiatric symptoms in adolescents. When choosing the study population we opted for two schools that differ in terms of academic performance and urbanicity, in order to get a broader sample. The first school that responded positively to our request to participate was Gymnasieskolan Spyken in Lund, with 1,018 students. Spyken is a large upper secondary school with programs intended to prepare students for university studies. It is situated in Lund, a traditional university city and part of the Metropolitan Malmö region (662,941 inhabitants in 2011) (Statistiska Centralbyrån, 2013). Spyken has high academic performance. The second school, Bergska skolan in the town of Finspång, has an average academic performance. Bergska skolan has 385 students and is the only upper secondary school in 
Finspång with national education programs. Finspång is a rural town (20,747 inhabitants in 2010) (Statistiska Centralbyrån, 2013) with heavy industry (Antonson, Thorsén, Sundquist, \& Sundquist, 2014).

All Swedish-speaking students, aged 15-19 years, were invited to participate via letters sent to their home addresses. Out of 1,403 potential participants, 283 gave written informed consent.

\subsection{Questionnaires and Computer Programs}

The measurements of perceived stress were based on the widely used 14-item PSS, PSS-14, constructed as a five-point Likert scale. The PSS does not reveal the magnitude of stressors, only how the individual experiences the situation. It has adequate test-retest reliability and internal consistency (Cohen, Kamarck, \& Mermelstein, 1983; Martin, Kazarian, \& Breiter, 1995; Mikolajczyk, Maxwell, Naydenova, Meier, \& El Ansari, 2008; Schmeelk-Cone \& Zimmerman, 2003). The PSS-14 has been shown to be interpreted and measured in the same way in both sexes (Cohen et al., 1983; Eskin \& Parr, 1996; Lavoie \& Douglas, 2012). A 2012 review of 11 studies also showed that the instrument has good internal consistency and high test-retest reliability (Lee, 2012). Measurements of perceived stress are reported to have higher ecological validity than physiological response parameters and self-report of psychiatric symptoms (Lavoie \& Douglas, 2012). The PSS has been empirically validated in college students (Lee, 2012) and has been used in adolescents in clinical and normal populations to predict outcomes such as depression, anxiety and underachievement (Suldo, Shaunessy, \& Hardesty, 2008). For comparison, we used the mean score for Swedish university students (mean age 25.4 years) from a 1996 validation study of the translation of the questionnaire into Swedish, where both males and females scored 24.4 on the PSS scale (Eskin \& Parr, 1996).

To evaluate psychiatric symptoms we used the symptoms checklist 90, SCL-90 (Derogatis, 1994). It uses a five-point Likert scale to assess overall psychiatric health in 90 items. The SCL-90 has been used in the USA since 1970 and is considered a central instrument for measuring psychiatric symptoms in Sweden as well (Socialstyrelsen). The results of SCL-90 are presented as a Global Severity Index (GSI), which is calculated as the total sum of the weights for each individual item divided by the total number of answered questions (with a minimum answer rate of $80 \%$ ). SCL-90 also contains nine sub-scales: Somatization, Obsessive compulsivity, Interpersonal sensitivity, Depression, Anxiety, Hostility, Phobic anxiety, Paranoid ideation, and Psychoticism. The SCL-90 is commonly used in psychiatric health evaluations. It has been shown to have satisfactory internal consistency reliability (Derogatis, Rickels, \& Rock, 1976; Horowitz, Rosenberg, Baer, Ureño, \& Villaseñor, 1988). Test-retest reliability coefficients were satisfactory both with a 1 week (Derogatis, 1994) and a 10 week pause (Horowitz et al., 1988). The validity of the scale has been confirmed with regard to internal structure, factorial invariance, and convergent-discriminant validity (Derogatis, 1994; Derogatis et al., 1976; Koeter, 1992; Wiznitzer, Verhulst, Van den Brink, \& Koeter, 1992). SCL-90 has been cited approximately 3,500 times since its introduction in 1973, which reflects its ecological validity (Bech, Bille, Møller, Hellström, \& Ostergaard, 2014). For comparisons, we used values for GSI and the sub-scales from a study from 1998 that was based on 2 776 healthy Swedish adolescents (age 17-20 years) (females, $n=2305$; males, $n=471$ ) (Fridell, 2002).

All questionnaires were copied from paper forms into the internet-based survey program Inquisite Survey System (Inquisite Inc., Copenhagen, Denmark). The tests were e-mailed to the addresses given by the students when they signed the informed consent forms. The students were allowed to answer the tests during a window of 10 consecutive days in order to avoid questionnaire fatigue. Only one response per student and test was possible. Using Inquisite Survey System allowed the incoming answers to be directly transferred to a database at our university department and to be further exported to statistical software without any human involvement at this stage, thus reducing errors due to data transfer. Data was stored in a non-identifiable form to preserve anonymity.

\subsection{Statistics}

All statistical analyses were conducted in Stata MP12 (StataCorp, Texas, USA). We used the Student's t-test to compare the results between the study population and the reference group. The values from the reference groups from 1996 and 1998 are presented as means and standard deviations; thus, although the scales are ordinal, a non-parametric test could not be used. Confidence intervals were calculated with a confidence level of $95 \%$. To calculate correlations between perceived stress and psychiatric symptoms we used Spearman's rank correlation coefficient, as the data were collected from Likert scales and hence were non-parametric. Differences compared to the reference groups were analyzed by one-sample t-test. 


\subsection{Ethical Standards}

We acquired the required permission for the study from the local ethics committee (Etikprövningsnämnden) in Lund (reference no. 2011/345). The complete study was registered at www.clinicaltrials.gov (reference NCT01457222) before it was started. The authors assert that all procedures contributing to this work comply with the ethical standards of the relevant national and institutional committees on human experimentation and with the Declaration of Helsinki, as revised in 2008. All participants gave written informed consent.

\section{Results}

\subsection{Personal Characteristics}

A total of 283 (20\%) students showed interest in participating in the study. Of these, 194 students (138 female, 48 male, 8 without specification of sex) answered the questionnaires, resulting in a response rate of $69 \%$ of those who gave informed consent. Bergska skolan provided 45 students (representing $12 \%$ of the total number of students at Bergska skolan) and 147 students came from Spyken (representing 14\% of the total number of students at Spyken). The vast majority of the students (98\%) were assigned to programs intended for preparation for university studies. The mean age was 16.9 and the median age was 17 (range: 15-19 years). Not all students gave information regarding their school and/or sex, which explains the discrepancies in the values of $\mathrm{n}$ in the tables.

\subsection{PSS}

Table 1 shows the median and mean values for PSS in 2011 and the mean values in 1996. Both female and male students had a significantly higher PSS values in 2011, compared with the reference value of 24.4 from 1996 (Table 1). The mean value was 24.4 in 1996 for both females and males. In 2011 the mean value was 28.9 for females and 26.2 in males. No statistically significant difference was observed, when we compared the values in 2011 between female and male students. Seven participants answering this questionnaire did not specify their sex.

Table 1. PSS in relation to sex and in comparison with the reference group from 1996

\begin{tabular}{lcccc}
\hline Variable & Total & Female & Male & Female vs. Male \\
\hline $\mathrm{n}, 2011$ & 179 & 127 & 45 & \\
PSS, median (IQR), 2011 & $28(11)$ & $28.5(10)$ & $26.5(12.5)$ & $\mathrm{p}=0.12$ \\
PSS, mean (SD), 2011 & $28.3(8.2)$ & $28.9(8.1)$ & $26.2(8.2)$ & \\
PSS, mean (SD), 1996 & $24.4(8.0)$ & $24.4(7.2)$ & $24.4(8.7)$ & \\
& $\mathrm{p}<0.0001$ & $\mathrm{p}<0.0001$ & $\mathrm{p}=0.0086$ & \\
\hline
\end{tabular}

\subsection{SCL-90}

For both female and male students the scores for total GSI were significantly higher in 2011, compared with the values from the 1998 study (Table 2). This was also observed for the subscales obsessive compulsivity, Depression, Anxiety, and Psychoticism. For Phobic anxiety, only female students had significantly higher values in 2011 compared with the values from 1998. No difference was observed for the Somatization, Interpersonal sensitivity, Hostility, and Paranoid ideation sub-scales.

When comparing the 2011 results between female and male students, female students had significantly higher values for total GSI as well as for the Somatization, Interpersonal sensitivity, Depression, Anxiety, Phobic anxiety, and Paranoid Ideation sub-scales (Table 2). No sex differences were observed for Obsessive Compulsivity, Hostility and Psychoticism. 
Table 2. SCL-90 in 2011 compared with the reference group from 1998. Significant p-values in bold

\begin{tabular}{|c|c|c|c|c|c|c|c|c|}
\hline \multirow[t]{2}{*}{ Variable } & & \multicolumn{3}{|c|}{ Reference population, 1998} & \multicolumn{3}{|c|}{ Our study population, 2011} & \multirow[b]{2}{*}{ Female vs. Male 2011} \\
\hline & & Total & Female & Male & Total & Female & Male & \\
\hline n & & 2776 & 2305 & 471 & 194 & 138 & 48 & \\
\hline \multirow[t]{2}{*}{ GSI } & mean (SD) & 0.71 & $0.76(0.54)$ & $0.45(0.41)$ & $0.84(0.55)$ & $0.89(0.55)$ & $0.65(0.48)$ & $\mathrm{p}=0.0028$ \\
\hline & vs. ref & & & & $\mathrm{p}=0.0005$ & $\mathrm{p}=0.0023$ & $\mathrm{p}=0.0036$ & \\
\hline \multirow[t]{2}{*}{ Somatization } & mean (SD) & 0.68 & $0.73(0.63)$ & $0.45(0.46)$ & $0.72(0.63)$ & $0.79(0.64)$ & $0.48(0.48)$ & $\mathrm{p}=0.0012$ \\
\hline & vs. ref & & & & $\mathrm{p}=0.18$ & $\mathrm{p}=0.30$ & $\mathrm{p}=0.36$ & \\
\hline \multirow{2}{*}{$\begin{array}{l}\text { Obsessive } \\
\text { compulsivity }\end{array}$} & mean (SD) & 0.99 & $1.04(0.68)$ & $0.72(0.57)$ & $1.26(0.74)$ & $1.29(0.75)$ & $1.12(0.69)$ & $\mathrm{p}=0.08$ \\
\hline & vs. ref & & & & $\mathrm{p}<0.0001$ & $\mathrm{p}=0.0001$ & $\mathrm{p}=0.0001$ & \\
\hline \multirow{2}{*}{$\begin{array}{l}\text { Interpersonal } \\
\text { sensitivity }\end{array}$} & mean (SD) & 0.80 & $0.86(0.69)$ & $0.52(0.5)$ & $0.82(0.67)$ & $0.89(0.67)$ & $0.61(0.63)$ & $\mathrm{p}=0.006$ \\
\hline & vs. ref & & & & $\mathrm{p}=0.332$ & $\mathrm{p}=0.322$ & $\mathrm{p}=0.17$ & \\
\hline \multirow[t]{2}{*}{ Depression } & mean (SD) & 0.95 & $1.04(0.74)$ & $0.52(0.53)$ & $1.19(0.78)$ & $1.27(0.77)$ & $0.95(0.73)$ & $\mathrm{p}=0.0066$ \\
\hline & vs. ref & & & & $\mathrm{p}=0.0000$ & $\mathrm{p}=0.0004$ & $\mathrm{p}=0.0001$ & \\
\hline \multirow[t]{2}{*}{ Anxiety } & mean (SD) & 0.69 & $0.75(0.66)$ & $0.41(0.47)$ & $0.96(0.7)$ & $1.06(0.71)$ & $0.65(0.52)$ & $\mathrm{p}=0.0002$ \\
\hline & vs. ref & & & & $\mathbf{p}<0.0001$ & $\mathrm{p}<0.0001$ & $\mathrm{p}=0.0012$ & \\
\hline \multirow[t]{2}{*}{ Hostility } & mean (SD) & 0.64 & $0.67(0.7)$ & $0.51(0.59)$ & $0.56(0.62)$ & $0.58(0.62)$ & $0.45(0.56)$ & $\mathrm{p}=0.11$ \\
\hline & vs. ref & & & & $\mathrm{p}=0.96$ & $\mathrm{p}=0.96$ & $\mathrm{p}=0.76$ & \\
\hline \multirow[t]{2}{*}{ Phobic anxiety } & mean (SD) & 0.24 & $0.27(0.45)$ & $0.12(0.3)$ & $0.33(0.54)$ & $0.35(0.53)$ & $0.18(0.36)$ & $\mathrm{p}=0.02$ \\
\hline & vs. ref & & & & $\mathrm{p}=0.009$ & $\mathrm{p}=0.04$ & $\mathrm{p}=0.13$ & \\
\hline \multirow[t]{2}{*}{ Paranoid ideation } & mean (SD) & 0.65 & $0.69(0.68)$ & $0.45(0.51)$ & $0.68(0.64)$ & $0.73(0.66)$ & $0.46(0.53)$ & $\mathrm{p}=0.005$ \\
\hline & vs. ref & & & & $\mathrm{p}=0.28$ & $\mathrm{p}=0.21$ & $\mathrm{p}=0.44$ & \\
\hline \multirow[t]{2}{*}{ Psychoticism } & mean (SD) & 0.33 & $0.37(0.5)$ & $0.12(0.41)$ & $0.51(0.52)$ & $0.53(0.49)$ & $0.45(0.55)$ & $\mathrm{p}=0.20$ \\
\hline & vs. ref & & & & $\mathbf{p}<\mathbf{0 . 0 0 0 1}$ & $\mathrm{p}=0.0001$ & $\mathrm{p}=0.0001$ & \\
\hline
\end{tabular}

\subsection{Correlation PSS and GSI}

In the 2011 study population, there was a significant correlation between PSS and GSI in both sexes (Table 3).

Table 3. Correlations between perceived stress and GSI

\begin{tabular}{lccc}
\hline Variable & PSS, Total & PSS, Female & PSS, Male \\
\hline GSI, $\mathrm{n}$ & 177 & 127 & 46 \\
GSI, $\rho$ & 0.67 & 0.69 & 0.60 \\
GSI, $\mathrm{p}$-value & $\mathrm{p}<0.0001$ & $\mathrm{p}<0.0001$ & $\mathrm{p}<0.0001$ \\
\hline
\end{tabular}

Note. $\rho=$ Spearman's rank correlation coefficient.

\section{Discussion}

The main findings of this study were that the prevalence of perceived stress (PSS) and overall psychiatric symptoms (total GSI) among Swedish upper secondary school students (both female and male students) were higher in 2011, in comparison with the Swedish reference populations from 1996 and 1998. For GSI, four out of 
nine subscales, i.e., Obsessive compulsivity, Depression, Anxiety, and Psychoticism were higher in 2011 in both female and male students. For Phobic anxiety, only female students had higher values in 2011.

In 2011, the mean values in perceived stress for female students was 28.9 and for male students it was 26.2. This potential difference in perceived stress between female and male students was, however, not statistically significant $(\mathrm{p}=0.12)$.

Female students had significantly higher values for total GSI than the male students in 2011. In addition, female students also had significantly higher values for six of the nine sub-scales in the GSI: Somatization, Interpersonal sensitivity, Depression, Anxiety, Phobic anxiety, and Paranoid Ideation. For the remaining three of the nine sub-scales, Obsessive compulsivity, Hostility, and Psychoticism, no gender differences were observed.

Perceived stress correlated well with the overall psychiatric symptoms $(\rho=0.67)$.

Our findings that Swedish adolescents aged 15-19 years reported higher levels of perceived stress and psychiatric symptoms, in comparison with results from previous reference populations, concur with earlier Swedish studies (Bremberg, 2006; Folkhälsomyndigheten, 2010; Hagquist \& Forsberg, 2007; Petersen, 2007). The present study adds to these relatively few previous studies as it is based on internationally validated questionnaires (rather than single questions) among older Swedish adolescents, which makes it easier to compare study findings over time as well as to compare findings between sexes.

Other high-income countries have also noted potential increases in psychiatric disorders among young people and this increase appears to be the continuation of a trend that started after World War II (Birmaher et al., 1996; Bremberg, 2006; Weissman \& Klerman, 1992).

The increase in psychiatric disorders among young people over time is unlikely to be related to substantial genetic changes in the population. Hence, mechanisms behind this increase must be sought in the environment (Birmaher et al., 1996).

A 1995 study, conducted by Rutter and Smith, reviewed several hypothetical explanations behind the observed increase in psychiatric disorders among young people in the postwar period (Rutter \& Smith, 1995). They found support for two possible explanations. The first was the general increase of alcohol consumption in society, which in turn can lead to alcohol use disorders among individuals. The second explanation was that the gap between young people's expectations and actual possibilities in life might have increased over time. The net result is paradoxical, since the experience of failure increases even though actual living conditions have improved (Rutter \& Smith, 1995). Other researchers have presented similar theories (Beck, 1992).

Highly individualistic, secularised societies have also been proposed as a contributor to an increased risk of developing psychiatric problems for individuals (Eckersley \& Dear, 2002; Maercker, 2001; Neeleman \& Lewis, 1999). Bremberg et al. referred to the individualisation in the industrialised society, with life being less predictable than before, as a potential explanation behind the increase in psychiatric problems (Bremberg, 2006). However, psychiatric disorders seem to have increased worldwide, i.e., in both industrialised and less developed countries (Gore et al., 2011). Finally, the increase in diagnosed psychiatric disorders among young people over time may be due to a change in attitude towards psychiatric health problems, with the more recent expectation that issues of this kind are something that should not only be accepted but also acted upon (Bremberg, 2006).

Our findings that female students reported more psychiatric symptoms than male students concur with previous studies that were based on a lesser number of questions (Bremberg, 2006; Folkhälsomyndigheten, 2010; Hagquist \& Forsberg, 2007; Petersen, 2007) rather than validated questionnaires. One study used three scales (the internationally validated Hospital Anxiety and Depression (HAD) scale, a questionnaire measuring perceived stress and sleep and a questionnaire measuring subjective health complaints) on upper secondary school students aged 16-17 years from northern Sweden in 2007-2008. The study showed a high prevalence of subjective health complaints and perceived stress, particularly among adolescent girls (Wiklund et al., 2012).

It has been recommended to include both internalizing and externalizing symptoms when measuring Swedish adolescents' psychiatric health because boys tend to report more externalizing problems and girls more internalizing symptoms (Hagquist, 2010). Our study was based on the SCL-90 that includes subscales covering both internalizing and externalizing symptoms. In 2011, it was only internalizing symptoms that were higher compared with the reference population from 1998. The internalizing symptoms, as measured in the subscales Obsessive compulsivity, Depression, and Anxiety were higher in both female and male students, whereas Phobic anxiety had higher values only in female students. A similar pattern was also observed in earlier Swedish evaluations (Beckman \& Hagquist, 2010; Cederblad, 2013). 
Many different explanations have been suggested regarding the observed sex differences in psychiatric symptoms. Biological changes during puberty have been closely linked to depression, as rising hormonal levels potentiate the risk of depression through mechanisms that are unrelated to the psychosocial effects of morphological changes in girls' bodies (Angold, Costello, Erkanli, \& Worthman, 1999).

Interpersonal stress models have linked girls' vulnerability to emotional distress to their social relationships (Rudolph, 2002). The symptom-perception theory proposes a gender difference in how individuals pay attention to, define, and react to psychiatric symptoms (Gijsbers Van Wijk \& Kolk, 1997; Hetland, Torsheim, \& Aaro, 2002). Earlier hypotheses have also suggested that women are more emotional and have more expressive behavior than men (Simon \& Nath, 2004) but this has subsequently been rejected by Bogner and Gallo (Bogner \& Gallo, 2004). Women in the USA report that they feel anxious and sad more often than men, but the common cultural assumption that women express feelings more often than men seems to be false (Simon \& Nath, 2004).

Social constructions of gender are possible explanations, which the cross-national study Health Behavior in School-aged Children (HBSC) found support for when comparing health complaints reported by 11- to 15-year-olds from 29 European and North American countries in 1997-1998 (Torsheim et al., 2006). Wiklund et al. also suggest that contextual factors, including social constructs and practices of gender, are of importance for the stress experienced by young Swedish women 16-25 years of age (Wiklund, Bengs, Malmgren-Olsson, \& Ohman, 2010).

Finally, there is a clear correlation between lower social positions, which women often have, and anxiety and sadness (Simon \& Nath, 2004).

Our findings of a strong association between perceived stress and overall psychiatric symptoms were consistent with previous research. Strong associations have also been found for perceived stress, psychosomatic symptoms, and anxiety (Wiklund et al., 2012). There is also growing evidence of a significant relationship between psychosocial stress and psychopathology in children and adolescents from both cross-sectional (Compas, 1987; Compas, Connor-Smith, Saltzman, Thomsen, \& Wadsworth, 2001) and longitudinal studies (Hammen \& Goodman-Brown, 1990; Hilsman \& Garber, 1995; Rudolph, Lambert, Clark, \& Kurlakowsky, 2001; Schmeelk-Cone \& Zimmerman, 2003).

\subsection{Limitations and Strengths}

This study had a cross-sectional design and hence no conclusions on causality could be drawn. Further, it is not possible to draw any conclusions about whether the high levels of perceived stress and psychiatric symptoms reported in 2011 depended on particular characteristics of the students that participated in the study (e.g., were more stressed and thus were more motivated to act on the subject than the non-participating students), or if the difference is explained by a true increase in perceived stress and psychiatric symptoms over time.

All instruments for measuring stress and stress-related variables were based on self-report questionnaires. Although a good correlation between self-reporting and general health was found in upper secondary school students in the Nordic countries (Breidablik, Meland, \& Lydersen, 2009), the method has implications for the objectivity of the data.

Furthermore, the previous PSS data that we used for comparison over time was collected from university students. Although the comparison population was somewhat older than our study population, Schmeelk-Cone and Zimmerman found that the PSS values remained basically unchanged when they repeatedly assessed the same individuals between 15-20 years of age (Schmeelk-Cone \& Zimmerman, 2003).

These limitations are, however, balanced by the strengths of this study. Most importantly, there is still a scarcity of Swedish studies on this age group using questionnaires that are well defined, validated, reliable, and that have previously been used in clinically relevant studies on adolescents to measure perceived stress and psychiatric symptoms. Thus, this study serves as an important contribution to previous studies. The non-response rate was in line with the dropout rate in similar studies on this population such as the "Malmö students Life and Drug habits" that has been referred to in governmental reports. That study was conducted five times between 1994 and 2006; the dropout rate varied between $77 \%$ and $96 \%$ (Petersen, 2007). Finally, when selecting the study population we opted for two schools that differed in terms of socioeconomic status, academic proficiency profile, urbanicity, and geographic location with the aim of getting a sample as representative as possible. This has been asked for in previous studies (Schraml, Perski, Grossi, \& Makower, 2012; Suldo et al., 2008). 


\subsection{Conclusion}

The present study showed that the prevalence of perceived stress (PSS) and overall psychiatric symptoms (total GSI) among Swedish upper secondary school students (both female and male students) were higher in 2011, in comparison with Swedish reference populations from 1996 and 1998. In addition, girls reported more psychiatric symptoms than boys and the level of perceived stress correlated well with the psychiatric symptoms. These findings should be useful for adolescents, parents, school and health care personnel as well as policymakers. Future studies are necessary in order to investigate the underlying causes and develop strategies to cope with the observed high levels of stress as well as to prevent the development of psychiatric symptoms.

\subsection{Key Points}

- Previous studies in adolescents have rarely used validated questionnaires to assess stress and psychiatric symptoms.

- This study used validated questionnaires, which showed that Swedish adolescents report high levels of perceived stress and psychiatric symptoms, especially in girls.

- Levels of perceived stress correlated well with the psychiatric symptoms.

- These findings are useful for school and health care policies.

\section{Acknowledgements}

We would like to thank the staff and the students at Bergska Skolan and Gymnasieskolan Spyken. We also thank Science Editors Stephen Gilliver and Patrick Reilly for correcting the language, and Karolina Palmér for statistical aid.

\section{Funding}

The Swedish Research Council for Health, Working Life and Welfare (In Swedish: Forte) and the Swedish Research Council to Jan Sundquist.

\section{References}

Angold, A., Costello, E. J., Erkanli, A., \& Worthman, C. M. (1999). Pubertal changes in hormone levels and depression in girls. Psychol Med, 29(5), 1043-1053. http://dx.doi.org/10.1017/S0033291799008946

Antonson, C., Thorsén, F., Sundquist, K., \& Sundquist, J. (2014). Stress-Related Symptoms in Swedish Adolescents: A Study in Two Upper Secondary Schools. Journal of Educational and Developmental Psychology, 4(2), 65-73. http://dx.doi.org/10.5539/jedp.v4n2p65

Bech, P., Bille, J., Møller, S. B., Hellström, L. C., \& Ostergaard, S. D. (2014). Psychometric validation of the Hopkins Symptom Checklist (SCL-90) subscales for depression, anxiety, and interpersonal sensitivity. Journal of Affective Disorders, 160, 98-103. http://dx.doi.org/10.1016/j.jad.2013.12.005

Beck, U. (1992). Risk society: Towards a new modernity. London: Sage.

Beckman, L., \& Hagquist, C. (2010). Hur mår barn och ungdomar i Sverige?: Analys av den officiella bilden, mediebilden och bilden från forskningen/Linda Beckman och Curt Hagquist: Karlstad: Centrum för forskning om barns och ungdomars psykiska hälsa. Karlstad universitet.

Birmaher, B., Ryan, N. D., Williamson, D. E., Brent, D. A., Kaufman, J., Dahl, R. E., ... Nelson, B. (1996). Childhood and adolescent depression: A review of the past 10 years. Part I. Journal of the American

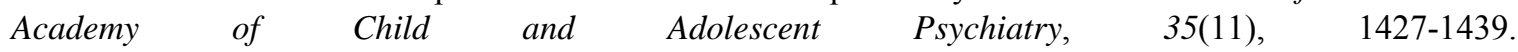
http://dx.doi.org/10.1097/00004583-199611000-00011

Bogner, H. R., \& Gallo, J. J. (2004). Are higher rates of depression in women accounted for by differential symptom reporting? Social Psychiatry \& Psychiatric Epidemiology, 39(2), 126-132. http://dx.doi.org/10.1007/s00127-004-0714-z

Bohman, H., Jonsson, U., Paaren, A., von Knorring, L., Olsson, G., \& von Knorring, A. L. (2012). Prognostic significance of functional somatic symptoms in adolescence: A 15-year community-based follow-up study of adolescents with depression compared with healthy peers. BMC Psychiatry, 12(1), 90. http://dx.doi.org/10.1186/1471-244X-12-90 
Breidablik, H. J., Meland, E., \& Lydersen, S. (2009). Self-rated health during adolescence: Stability and predictors of change (Young-HUNT study, Norway). European Journal of Public Health, 19(1), 73-78. http://dx.doi.org/10.1093/eurpub/ckn111

Bremberg, S. (2006). Ungdomar, stress och psykisk ohälsa. In Analyser och förslag till åtgärder (p. 15): Statistiska Centralbyrån.

Cederblad, M. (2013). Ungas psykiska hälsa förbryllar forskare. Retrieved from http://ludwig.lub.lu.se/login?url=http://search.ebscohost.com/login.aspx?direct=true\&db=edsswe\&AN=eds swe.oai.lup.lub.lu.se.4142941\&site $=$ eds-live \&scope $=$ site

Clark, C., Rodgers, B., Caldwell, T., Power, C., \& Stansfeld, S. (2007). Childhood and adulthood psychological ill health as predictors of midlife affective and anxiety disorders: The 1958 British Birth Cohort. Arch Gen Psychiatry, 64(6), 668-678. http://dx.doi.org/10.1001/archpsyc.64.6.668

Cohen, S., Kamarck, T., \& Mermelstein, R. (1983). A Global Measure of Perceived Stress. Journal of Health \& Social Behavior, 24(4), 385-396. http://dx.doi.org/10.2307/2136404

Compas, B. E. (1987). Coping with stress during childhood and adolescence. Psychological Bulletin, 101(3), 393-403. http://dx.doi.org/10.1037/0033-2909.101.3.393

Compas, B. E., Connor-Smith, J. K., Saltzman, H., Thomsen, A. H., \& Wadsworth, M. E. (2001). Coping with stress during childhood and adolescence: Problems, progress, and potential in theory and research. Psychological Bulletin, 127(1), 87-127. http://dx.doi.org/10.1037/0033-2909.127.1.87

Derogatis, L. R. (1994). SCL-90-R Administration, Scoring, and Procedures Manual (3rd ed.). Minneapolis, U.S.A.: NCS Pearson Inc.

Derogatis, L. R., Rickels, K., \& Rock, A. F. (1976). The SCL-90 and the MMPI: A step in the validation of a new self-report scale. Br J Psychiatry, 128(3), 280-289. http://dx.doi.org/10.1192/bjp.128.3.280

Eckersley, R., \& Dear, K. (2002). Cultural correlates of youth suicide. Social Science and Medicine, 55(11), 1891-1904. http://dx.doi.org/10.1016/S0277-9536(01)00319-7

Eskin, M., \& Parr, D. (1996). Introducing a Swedish version of an instrument measuring mental stress/Mehmet Eskin, Deirdre Parr. Stockholm: Univ., Department of Psychology.

Fergusson, D. M., Horwood, L. J., Ridder, E. M., \& Beautrais, A. L. (2005). Subthreshold depression in adolescence and mental health outcomes in adulthood. Arch Gen Psychiatry, 62(1), 66-72. http://dx.doi.org/10.1001/archpsyc.62.1.66

Folkhälsoinstitutet. (2005). Folkhälsopolitisk rapport. Stockholm: Statens folkhälsoinstitut.

Folkhälsomyndigheten. (2010). Folkhälsopolitisk rapport 2010: Framtidens folkhälsa-allas ansvar. Stockholm: Statens folkhälsoinstitut.

Folkhälsomyndigheten. (2014). Folkhälsan i Sverige, Årsrapport 2014. Solna/Östersund. Retrieved from http://www.folkhalsomyndigheten.se/publicerat-material/publikationer/Folkhalsan-i-Sverige-Arsrapport-20 $14 /$

Fridell, M. (2002). SCL-90: Svensk normering, standardisering och validering av symtomskalan/Mats Fridell. Stockholm: Statens institutionsstyrelse (SiS).

Gijsbers Van Wijk, C. M. T., \& Kolk, A. M. (1997). Sex differences in physical symptoms: The contribution of symptom perception theory. Social Science and Medicine, 45(2), 231-246. http://dx.doi.org/10.1016/S0277-9536(96)00340-1

Gore, F. M., Joseph, V., Mathers, C. D., Bloem, P. J. N., Ferguson, J., Patton, G. C., ... Sawyer, S. M. (2011). Global burden of disease in young people aged 10-24 years: A systematic analysis. The Lancet, 377(9783), 2093-2102. http://dx.doi.org/10.1016/S0140-6736(11)60512-6

Hagquist, C. (2010). Original article: Discrepant Trends in Mental Health Complaints Among Younger and Older Adolescents in Sweden: An Analysis of WHO Data 1985-2005. Journal of Adolescent Health, 46, 258-264. http://dx.doi.org/10.1016/j.jadohealth.2009.07.003

Hagquist, C., \& Forsberg, E. (2007). Ung i Värmland 1988-2005: En undersökning bland niondeklassare/Curt Hagquist, Erik Forsberg. Karlstad: Fakulteten för samhälls-och livsvetenskaper, Folkhälsovetenskap, Karlstads universitet. 
Hammen, C., \& Goodman-Brown, T. (1990). Self-schemas and vulnerability to specific life stress in children at risk for depression. Cognitive Therapy and Research, 14(2), 215-227. http://dx.doi.org/10.1007/BF01176210

Hetland, J., Torsheim, T., \& Aaro, L. E. (2002). Subjective health complaints in adolescence: Dimensional structure and variation across gender and age. Scand $J$ Public Health, 30(3), 223-230. http://dx.doi.org/10.1080/140349402320290953

Hilsman, R., \& Garber, J. (1995). A Test of the Cognitive Diathesis-Stress Model of Depression in Children: Academic Stressors, Attributional Style, Perceived Competence, and Control. Journal of Personality \& Social Psychology, 69(2), 370-380. http://dx.doi.org/10.1037/0022-3514.69.2.370

Hiyoshi, A., Udumyan, R., Osika, W., Bihagen, E., Fall, K., \& Montgomery, S. (2015). Stress resilience in adolescence and subsequent antidepressant and anxiolytic medication in middle aged men: Swedish cohort study. Social Science \& Medicine, 134, 43-49. http://dx.doi.org/10.1016/j.socscimed.2015.03.057

Hjern, A., Alfven, G., \& Ostberg, V. (2008). School stressors, psychological complaints and psychosomatic pain. Acta Paediatr, 97(1), 112-117. http://dx.doi.org/10.1111/j.1651-2227.2007.00585.x

Horowitz, L. M., Rosenberg, S. E., Baer, B. A., Ureño, G., \& Villaseñor, V. S. (1988). Inventory of interpersonal problems: Psychometric properties and clinical applications. Journal of Consulting and Clinical Psychology, 56(6), 885-892. http://dx.doi.org/10.1037/0022-006X.56.6.885

Koeter, M. W. J. (1992). Validity of the GHQ and SCL anxiety and depression scales: A comparative study. Journal of Affective Disorders, 24(4), 271-279. http://dx.doi.org/10.1016/0165-0327(92)90112-J

Landstedt, E., \& Gådin, K. G. (2012). Seventeen and stressed-Do gender and class matter? Health Sociology Review, 21(1), 82-98. http://dx.doi.org/10.5172/hesr.2012.21.1.82

Lavoie, J. A. A., \& Douglas, K. S. (2012). The perceived stress scale: Evaluating configural, metric and scalar invariance across mental health status and gender. Journal of Psychopathology and Behavioral Assessment, 34(1), 48-57. http://dx.doi.org/10.1007/s10862-011-9266-1

Lee, E. H. (2012). Review of the Psychometric Evidence of the Perceived Stress Scale. ASIAN NURSING RESEARCH, 6(4), 121-127. http://dx.doi.org/10.1016/j.anr.2012.08.004

Loeber, R., \& Farrington, D. P. (2000). Young children who commit crime: Epidemiology, developmental origins, risk factors, early interventions, and policy implications. Dev Psychopathol, 12(4), 737-762. http://dx.doi.org/10.1017/S0954579400004107

Maercker, A. (2001). Association of cross-cultural differences in psychiatric morbidity with cultural values: A secondary data analysis. German Journal of Psychiatry, 4(1), 17-23.

Martin, R. A., Kazarian, S. S., \& Breiter, H. J. (1995). Perceived stress, life events, dysfunctional attitudes, and depression in adolescent psychiatric inpatients. Journal of Psychopathology and Behavioral Assessment, 17(1), 81-95. http://dx.doi.org/10.1007/BF02229205

Mathers, C. D., \& Loncar, D. (2006). Projections of Global Mortality and Burden of Disease from 2002 to 2030. PLoS Medicine, 3(11), 2011-2030. http://dx.doi.org/10.1371/journal.pmed.0030442

Mikolajczyk, R. T., Maxwell, A. E., Naydenova, V., Meier, S., \& El Ansari, W. (2008). Depressive symptoms and perceived burdens related to being a student: Survey in three European countries. Clinical Practice And Epidemiology In Mental Health: CP \& EMH, 4, 19. http://dx.doi.org/10.1186/1745-0179-4-19

Murray, C. J., Vos, T., Lozano, R., Naghavi, M., Flaxman, A. D., Michaud, C., ... Memish, Z. A. (2012). Disability-adjusted life years (DALYs) for 291 diseases and injuries in 21 regions, 1990-2010: A systematic analysis for the Global Burden of Disease Study 2010. Lancet, 380(9859), 2197-2223. $\mathrm{http}: / / \mathrm{dx}$.doi.org/10.1016/S0140-6736(12)61689-4

Murray, L. (1996). The global burden of disease: Summary. Geneva : WHO, 1996.

Neeleman, J., \& Lewis, G. (1999). Suicide, religion, and socioeconomic conditions. An ecological study in 26 countries, 1990. J Epidemiol Community Health, 53(4), 204-210. http://dx.doi.org/10.1136/jech.53.4.204

Nygren, K., Bergström, E., Janlert, U., \& Nygren, L. (2012). Parents matter-but relations to parents do not explain gender differences in self-reported health in adolescents. Scandinavian Journal of Caring Sciences, 26(4), 643-653. http://dx.doi.org/10.1111/j.1471-6712.2012.00973.x 
Patel, V., Flisher, A. J., Hetrick, S., \& McGorry, P. (2007). Mental health of young people: A global $\begin{array}{llll}\text { public-health } & \text { challenge. } & \text { 369(9569), } & \text { 1302-1313. }\end{array}$ http://dx.doi.org/10.1016/S0140-6736(07)60368-7

Petersen, S. (2007). Barns och ungdomars psykiska hälsa i Sverige. En systematisk litteraturöversikt med tonvikt på förändringar över tid. Hälsoutskottet.

Ravens-Sieberer, U., Ottova, V., Erhart, M., Torsheim, T., Hetland, J., Vollebergh, W., ... Erginoz, E. (2009). Subjective health, symptom load and quality of life of children and adolescents in Europe. International Journal of Public Health, 54(SUPPL. 2), 151-159. http://dx.doi.org/10.1007/s00038-009-5406-8

Rudolph, K. D. (2002). Gender differences in emotional responses to interpersonal stress during adolescence. Journal of Adolecent Health, 30(4), 3-13. http://dx.doi.org/10.1016/S1054-139X(01)00383-4

Rudolph, K. D., Lambert, S. F., Clark, A. G., \& Kurlakowsky, K. D. (2001). Negotiating the Transition to Middle School: The Role of Self-Regulatory Processes. Child Dev, 3, 929. http://dx.doi.org/10.1111/1467-8624.00325

Rutter, M., \& Smith, D. J. (1995). Psychosocial disorders in young people: Time trends and their causes. Chichester: Wiley for Academia Europaea.

Schmeelk-Cone, K. H., \& Zimmerman, M. A. (2003). A Longitudinal Analysis of Stress in African American Youth: Predictors and Outcomes of Stress Trajectories. Journal of Youth and Adolescence, 32(6), 419-430. http://dx.doi.org/10.1023/A:1025934301468

Schraml, K., Perski, A., Grossi, G., \& Makower, I. (2012). Chronic Stress and Its Consequences on Subsequent Academic Achievement among Adolescents. Journal of Educational \& Developmental Psychology, 2(1), 69. http://dx.doi.org/10.5539/jedp.v2n1p69

Simon, R. W., \& Nath, L. E. (2004). Gender and Emotion in the United States: Do Men and Women Differ in Self-Reports of Feelings and Expressive Behavior? American Journal of Sociology, 109(5), 1137-1176. http://dx.doi.org/10.1086/382111

Socialstyrelsen. SCL 90 (Symptoms checklist). (n.d.).

Statistiska Centralbyrån. (2013). Befolkningstäthet (invånare per kvadratkilometer), folkmängd och landareal efter region och kön. År 1991-2012 (Webpage). Retrieved from http://www.scb.se/Pages/SSD/SSD_SelectVariables__340487.aspx?rxid=2e59168f-8cad-414b-bc36-afb8 21920ec9\&px_tableid=ssd_extern\%3aBefArealTathetKon\&deltabellid=K1

Suldo, S. M., Shaunessy, E., \& Hardesty, R. (2008). Relationships among stress, coping, and mental health in high-achieving high school students. Psychology in the Schools, 45(4), 273-290. http://dx.doi.org/10.1002/pits.20300

Torsheim, T., Ravens-Sieberer, U., Hetland, J., Valimaa, R., Danielson, M., \& Overpeck, M. (2006). Cross-national variation of gender differences in adolescent subjective health in Europe and North America. Soc Sci Med, 62(4), 815-827. http://dx.doi.org/10.1016/j.socscimed.2005.06.047

Torsheim, T., \& Wold, B. (2001). School-related stress, support, and subjective health complaints among early adolescents: A multilevel approach. J Adolesc, 24(6), 701-713. http://dx.doi.org/10.1006/jado.2001.0440

Weissman, M. M., \& Klerman, G. L. (1992). Depression: Current understanding and changing trends. Annual Review of Public Health, 13, 319-339. http://dx.doi.org/10.1146/annurev.pu.13.050192.001535

Wiklund, M., Bengs, C., Malmgren-Olsson, E. B., \& Ohman, A. (2010). Young women facing multiple and intersecting stressors of modernity, gender orders and youth. Soc Sci Med, 71(9), 1567-1575. http://dx.doi.org/10.1016/j.socscimed.2010.08.004

Wiklund, M., Malmgren-Olsson, E. B., Öhman, A., Bergström, E., \& Fjellman Wiklund, A. (2012). Subjective health complaints in older adolescents are related to perceived stress, anxiety and gender: A cross-sectional school study in Northern Sweden. BMC Public Health, 12(1), 993-1005. http://dx.doi.org/10.1186/1471-2458-12-993

Wiznitzer, M., Verhulst, F. C., Van den Brink, W., \& Koeter, M. (1992). Detecting psychopathology in young adults: The Young Adult Self Report, the General Health Questionnaire and the Symptom Checklist as 


$\begin{array}{lccccc}\text { screening Acta } & \text { instruments. Psychiatrica } & \text { Scandinavica, } & 86(1), & 32-37 . \\ \text { http://dx.doi.org/10.1111/j.1600-0447.1992.tb03221.x }\end{array}$

\section{Copyrights}

Copyright for this article is retained by the author(s), with first publication rights granted to the journal.

This is an open-access article distributed under the terms and conditions of the Creative Commons Attribution license (http://creativecommons.org/licenses/by/4.0/). 